\title{
'N ONTLEDING VAN DIE \\ WISKUNDIGE VERHOUDINGSBEGRIP VAN LEERLINGE IN STANDERDS AGT, NEGE EN TIEN
}

\section{Inleiding.}

In Suid-Afrika is onder Amerikaanse invloed die vormende waarde van sekere leervakke taamlik uit die oog verloor. Gevolglik het sommige middelbare skole van Rekenkunde 'n „keusevak” gemaak, met die gevolg dat die Rekenkunde-onderwys heeltemal op die agtergrond geraak het.

Vroeër was lees, skrywe en reken die drie hoekpilare van die onderwys. Die beleid om Rekenkunde hierdie sleutelposisie te ontsê, het reeds sy wrange vrugte gehad. Nie alleen is daar vandag 'n aansienlike aantal onderwysers en onderwyseresse aan beide middelbare en laer skole, wie se Rekenkunde-opleiding nie verder as standerd ses strek nie, maar daar word selfs beweer dat ons rekenvermoë aan die $k w y n$ is.

Die Rekenkundeleerplan vir die Transvaalse middelbare skole bepaal uitdruklik dat ingewikkelde berekeninge nêrens aangepak behoort te word nie. Die enigste moeilikhede wat leerlinge dan nog kan hê, is dat hulle die werk nie kan begryp nie.

Maar is Rekenkunde werklik so moeilik om te begryp? Dit s.ang van die rekenkundige begri $p_{r}$ af.

Om hierdie piobleem - die rekenmoeilikhede van middelbare skoolleerlinge - op te los, vereis 'n grondige studie van die belangrikste rekenkundige, en dus ook die wiskundige, begrippe.
Selfs 'n vlugtige ondersoek van die bogenoemde Rekenkundige leerplan toon dat die verhoudingsbegrip hier 'n sleutel. posisie beklee. Die berekening van persentasies, die berekenings in verband met enkelvoudige rente, kommissie, handelskorting, bankrotskappe, effekte en nog baie ander, is op die verhoudingsbegrip gegrond.

\section{Die probleemstelling.}

In die eerste plek is dit noodsaaklik dat daar 'n deeglike studie van die wiskundige verhoudingsbegrip, en die plek wat dit in die moderne denke beklee, gemaak word.

In die tweede plek moet beslis vasgestel word of die leerlinge wiskundige verhoudings begryp. Dit is moontlik dat sekere wiskundige begrippe wat deur die leerplan, leerboeke en onderwysers as vanselfsprekend en bekend aanvaar word, tog te gevorderd is vir leerlinge in die aanvangsklasse van die middelbare skool.

In die derde plek moet vasgestel word of die ontwikkeling van die wiskundige verhoudingsbegrip van leerlinge bevorderlik is vir hul vermoë om relasies ook op ander gebiede in te sien, en of dit op die wyse hul denke ten goede kom.

\section{Histories.}

Die getalbegrip van die ou Egiptenare' ), Babiloniërs en Grieke ${ }^{2}$ ) was 'n 
verhoudingsbegrip. Die ontdekking van die irrasionale, die onmeetbare, wat nie met die verhoudingsbegrip gestrook het nie, het 'n krisis in die Griekse Wiskunde veroorsaak. Dit het meegebring dat die ontwikkeling van die Wiskunde feitlik van die tweede eeu voor Christus tot die sewentiende eeu na Christus stilgestaan het ${ }^{3}$ ). Archimedes het die Infinitesimaalrekening verrassend ver ontwikkel ${ }^{4}$ ), maar daarna was daar stilstand, omdat daar aan die idee van "indivisibilia", dit is baie klein deeltjies, met ander woorde 'n atomistiese begrip, bly hang is.

Newton het die atomistiese begrip vervang deur 'n verhoudingsbegrip deur te konsentreer op die verhouding van deeltjies wat dan tot 'n limiet nader $\left.{ }^{5}\right)$. Dit was die begin van die moderne Integraalen Differensiaalrekening.

Die moderne wiskundige denke.

Die rol wat die verhoudingsbegrip in die moderne wiskundige denke speel, kan ons soos volg opsom:

Deur verhouding word die ruimtelike grootte van dinge as getalle uitgedruk. 'n Breuk is die betrekking tussen twee groothede.

'n Verhouding is in die taal van die wiskundige die betrekking tussen twee getalle ${ }^{6}$ ).

Denke en begripsvorming sielkundig beskou

Die woord „relatie" of „relation” kan soms deur "betrekking", en wanneer dit 'n meer wiskundige betekenis het, deur "verhouding" vervang word. Hierdie twee begrippe „betrekking” en „verhouding”, is baie nou aan mekaar verwant. 'n Ver- houding is 'n betrekking tussen twee getalle.

In die denke (begripsvorming, probleemoplossing) is betrekkings fundamenteel.

Volgens Meumann is die sien van betrekkings nie die intelligensie self nie, maar is die sine qua non vir intelligensie ${ }^{7}$ ).

In sy ondersoek oor die oordeel probeer Marbe 'n betrekking tussen inhoude bepaal ${ }^{8}$ ).

Volgens Sassenfeld bestaan die tweede laag van die denke uit die verhoudings van die aanskoulike, om in die derde laag die vorming van begrippe moontlik te maak $^{9}$ ).

Vir Duncker is produktiewe denke die skepping van 'n sinvolle verband uit leë betrekkings. Insig en "relatie-besef" is dieselfde ${ }^{10}$ ).

Spearman veronderstel nog dat die kennis van betrekkings van self na vore kom"l).

Vir Wertheimer is produktiewe pro. bleemoplossing afhanklik van die verstaan van die strukturele en funksionele, die innerlike betrekkings ${ }^{12}$ ).

Wiskundig: Indien 'n persoon die betrekking tussen twee getalle kan sien, beskik hy oor 'n verhoudingsbegrip.

Algemeen: Kan iemand die innerlike betrekkings in 'n probleem raaksien, dan beskik hy oor 'n nodige voorwaarde vir die oplossing daarvan. Ons kan dus verwag dat 'n persoon se verhoudingsbegrip 'n aanduiding sal wees van sy vermoë om enige probleem, waar betrekkingsinsig belangrik is, op te los.

Die verhoudingsbegrip van kinders.

Volgens Piaget het die kind aanvanklik 
'n eendimensionale verhoudingsbegrip. Wanneer hy vir die eerste maal skool toe gaan (leeftyd 6 jaar), kan hy reeds gelyktydige veranderinge in twee verskillende dimensies opmerk ${ }^{13}$ ).

Die standerd VI-leerling se verhoudingsbegrip is, volgens $W$ epener, reeds so ver ontwikkel dat hy by voorkeur van die breukmetode in die oplossing van eweredigheidsomme gebruik mak. Hy begaan nog foute deur te deel waar hy moes vermenigvuldig het, of omgekeerd ${ }^{14}$ ).

Veral leerlinge wat nog na standerd VI Rekenkunde neem, onthou die oplossingsmetodes goed, selfs nadat hulle reeds die middelbare skool (standerds VI tot $\mathrm{X})$ verlaat het.

Kohnstamm beskou die verhoudingsbegrip van die leerlinge wat vir die eerste keer na die middelbare skool gaan, as so swak dat hy twyfel of hulle met vrug wiskunde-onderwys kan ontvang ${ }^{15}$ ).

Sillogisme-ondersoeke het aangetoon dat die formeel-logiese denkprestasies van veertienjariges swakker is as die van dertienjariges. Turkstra meld egter dat die teenoorgestelde ook opgemerk is. ${ }^{16}$ ) Meisies het in die sillogisme-ondersoek beter gevaar as seuns. ${ }^{17}$ )

Teen hierdie vorm van ondersoek is o.a. deur Kohnstamm sterk besware geopper. ${ }^{18}$ )

$\mathrm{Om}$ die rekenkundige begripsvermoë van leerlinge in sts. VI, VII en VIII te toets, en meer in besonder die verhoudingsbegrip, het skrywer 'n toetsbattery opgestel.

Die vereistes wat aan die toetsbattery gestel is.

Omvang: Die battery bestaan uit vyf toetse. Die eerste toets is heeltemal nierekenkundig van aard, die tweede het rekenopgawes gehad oor direkte eweredigheid, die derde oor omgekeerde eweredig. heid, die vierde het die leerlinge se opmerksaamheid getoets, terwyl die vyfde toets meetkundig van aard was. In hierdie artikel sal alleen die eerste en die tweede toetse bespreek word.

Inhoud: Enige toets is in 'n mate 'n kennistoets. Omdat in hierdie toetse geen navraag gedoen sou word omtrent die proefpersone se kennis van die term "verhouding" nie, is die woord "verhouding" heeltemal weggelaat, en kom dit in geen vraag voor nie.

Die wiskundige verhoudingsbegrip van leerlinge word teen die agtergrond van betrekkings gesien. Daarom is die eerste toets nie 'n rekenkundige verhoudingstoets nie, maar word die leerlinge se ver. moë om die betrekkings tussen ongelykhede te bepaal vasgestel, sonder dat daar van getalle of van rekenkundige bewerking gebruik gemaak word.

Die tweede toets is opgestel met die doel om die wiskundige verhoudingsbegrip van leerlinge op rekenkundige gebied te toets, en bestaan uit direkte eweredigheidsomme.

Standaard: Die vrae van elke toets is van maklik tot moeilik gegradeer deur gebruik te makk van verskillende voortoetse, en is sover moontlik uit handboekies vir standerds vier en vyf verkry. Vir elke toets is 'n tydsbeperking vasgestel.

Vorm: Die vrae moes kort, duidelik en ondubbelsinnig wees, en van so 'n aard dat die antwoorde ook kort en duidelik kon wees. Die bewerkings moes so maklik moontlik wees. 
TOETS 1. (Tyd 5 minute).

Voorbeeld: Piet en Jan hardloop resies. Piet hardloop vinniger as Jan. Wie sal wen? Antwoord: Piet.

1. Skrywe die volgende weer neer, maar nou in volgorde van belangrikheid: Prinsipaal, skoolseun, onderwyser, inspekteur.

2. Johannesburg is 'n deel van die Witwatersrand. Watter is die grootste: die Witwatersrand of Johanneshurg?

3. 'n Plymouth ry vinniger as 'n Ford; 'n Chevrolet ry stadiger as 'n Ford; 'n Nash ry net so vinnig as 'n Chevrolet. Sal 'n Nash vinniger ry as ' $n$ Ply. mouth?

4. As jou ma my ma se suster is, wat is jou pa van my ma?

5. In volgorde van bo na onder het die Voortrekkervlag die volgende kleure: rooi, wit en blou. Skrywe nou eers die middelste kleur, dan die onderste en dan die boonste.

6. Twee motors het dieselfde gewig en ry ewe veel; die een het groot wiele en die ander het klein wieletjies. Watter motor se bande sal die gouste slyt?

7. As die trein van Johannesburg na Pretoria \inniger as gewoonlik ry, moet dit langer of korter stilstaan by die stasies tussenin, om die hele afstand in dieselfde tyd af te lê?

8. As water by ' $n$ dam vinniger uitstroom as instroom, sal dit lank neem voordat die dam vol is, of hoe?

9. Waarvoor het ek die grootste blikkie nodig, 'n pond water of 'n pond klipgruis?

10. Piet sê: „Ek is my pa se ma se suster se dogter se seun". Hoe kan jy dit verklaar?
TOETS 2 (Tyd 8 minute).

Voorbeeld: As water gepomp word teen 500 gellings per uur, hoeveel sal in 5 uur gepomp word? Antwoord: 2,500 gelling. 1. Hoe ver sal 'n motor teen 4,0 myl per uur ry in 3 uur?

2. Hoeveel pond lusernsaad is nodig om 5 akkers te saai, as 'n mens 60 pond saad vir 3 akkers nodig het?

3. In 'n drukkery is 'n masjien wat $\mathbf{4 0 0}$ koerante in 60 sekondes vou. Hoeveel sekondes sal dit neem om 1,000 koe. rante te vou?

4. Hoeveel is 116 groter as 42 ?

5. Vul in die ontbrekende getal in die volgende reeks: $61854 \quad \ldots . . .4861458$.

6. 'n Man word 18 sjielings en ses pennies betaal vir 6 uur se werk. Hoeveel moet hy kry vir 9 uur se werk?

7. As $2 \frac{1}{2}$ jaart materiaal 90 pennies kos, hoeveel pennies sal $3 \frac{1}{2}$ jaart kos?

8. Verdeel $\mathbf{4 8}$ morge grond tussen Jan en Piet, sodat vir elke 5 morge wat Jan kry, Piet 7 morge kry.

9. Verdeel $£ 56$ tussen Anna, Betta en Mieta, sodat Anna twee maal sovecl kry as Betta, en Betta twce maal soveel kry as Mieta.

10. As 100 dele kalk bestaan uit 40 dele kalsium, 12 dele koolstof en 48 dele suurstof, hoeveel ton koolstof sal daar in 120 ton kalk wees?

Tydsfaktor: In die tweede toets is die tydsfaktor van groot belang. Die aantal vrae wat 'n persoon in die vasgestelde tyd afhandel, sal grotendeels daarvan afhang of hy die nodige insig het om die bewerking volgens die breukmetode te doen. Word vraag 2 van Toets 2 volgens die cenheidsmetode gedoen, dan is die stappe soos volg: 
Vir 3 akkers is 60 pond saad nodig vir $l$ akker is $60 / 3=20$ pond saad nodig.

Vir 5 akkers is $5 \times 20=100$ pond saad nodig.

Daar is dus minstens twee stappe nodig. Volgens die breukmetode is die bewerking soos volg:

Daar is $5 / 3 \times 60 / 1=100$ pond saad nodig.

Hier word die som in een stap gedoen, met groot tydsbesparing.

Die resultate van die voortoets het duidelik geopenbaar dat sekere proefpersone die vrae baie vinniger kan beantwoord as andere. Van die 38 proefpersone in Standerd VIII het vier al tien vrae reg beantwoord: een seun na ses minute en een meisie na sewe-en-driekwart minute. Aan die ander kant het een proefpersoon in standerd VI na sewe minute nog geen vraag reg beantwoord nie. Om almal dus 'n billike kans te gee om sommige van die vrae te beantwoord, en selfs om in die uitsonderlike geval volpunte te behaal, is die tydsbeperking op $\mathbf{8}$ minute gestel.

TABEL I.

Die aantal proefpersone.

\section{SEUNS:}

$\begin{array}{lcccc}\text { Skool } & \text { ST. VI } & \text { St. VII } & \text { St. VIII } & \text { Totaal } \\ \text { A } & 76 & 79 & 37 & 192 \\ \text { B } & 63 & 106 & 109 & 278 \\ \text { C } & 66 & 52 & 50 & 168 \\ \text { D } & 103 & 143 & 81 & 327 \\ & - & & & \\ \text { Totaal } & 308 & 380 & 277 & 965\end{array}$

MEISIES:

$\begin{array}{lcccc}\text { Skool } & \text { St. VI } & \text { St. VII } & \text { St. VIII } & \text { Totaal } \\ \text { A } & 76 & 65 & 53 & 194\end{array}$

\begin{tabular}{|c|c|c|c|}
\hline B & 54 & 142 & 54 \\
\hline C & 59 & 67 & 51 \\
\hline D & 85 & 157 & 72 \\
\hline Гotaal & 274 & 431 & 230 \\
\hline
\end{tabular}

Die proefnemer, helpers en proefpersone.

Skool A is 'n betreklike jong middelbare skool op die Wes-Rand. Oorspronklik was daar net 'n laerskool, maar geleidelik in hoër standerds bygevoeg. Ten tyde van die ondersoek het die hoër afdeling pas die status van middelbare skool verkry. Vroeër was dit 'n Groep II-skool. In al vier die skole is die sogenaamde aanpassingsklasse nie getoets nie.

Skool B is 'n groot gevestigde skool in die suidelike voorstede van Johannesburg. Sommige van die standerd VI-klasse was nie in dieselfde gehou as die res van die skool nie, maar was in werklikheid die begin van 'n nuwe middelbare skool elders. Gevolglik is daar minder stan. derdsessers as standerdsewes getoets, en daar mag 'n mate van seleksie in die standerdsessers se guns gewees het.

Skool C is 'n groot middelbare skool in Oos-Transvaal. In die gebied wat deur die skool bedien is, is daar ' $n$ dwangkolonie van die Departement van Volks. welsyn, en 'n gedeelte van die leerlinge kom uit die kolonie. Verder kom die meeste leerlinge van klein plasies of kleinhoewes wat deel vorm van 'n groot besproeiingskema.

Skool D is ' $n$ baie groot skool in 'n welvarende Wes-Transvaalse distrik. Die standerdsessers is minder as die standerdsewes omdat sommige standerdsesklasse nog by die laerskole was. Die seleksiefaktor sal dus maar gering wees. Die leer- 
linge in standerds VI, VII en VIII van hierdie skole het as proefpersone opgetree, en hulle onderwysers as helpers van die proefnemer. Die skrywer het persoonlik as proefnemer opgetree. Die aantal proefpersone verskyn in Tabel $I$.

Die resultate van die toetse.

Toets $I$. Die gemiddelde persentasies wat in Toets $I$ behaal is, verskyn in Tabel II.

\section{TABEL II}

Die gemiddelde persentasies deur die proefpersone behaal in Toets $I$.

SEUNS:

$\begin{array}{lccc}\text { Skool } & \text { St. VI } & \text { St. VII } & \text { St.VIII } \\ \text { A } & 52.4 & 55.8 & 67.3 \\ \text { B } & 57.3 & 54.1 & 61.2 \\ \text { C } & 49.4 & 57.5 & 72.8 \\ \text { D } & 53.3 & 63.0 & 68.4\end{array}$

MEISIES :

$\begin{array}{lccc}\text { Skool } & \text { St. VI } & \text { St. VII } & \text { St.VIII } \\ \text { A } & 43.8 & 53.1 & 63.0 \\ \text { B } & 48.1 & 49.9 & 56.7 \\ \text { C } & 54.1 & 55.5 & 61.6 \\ \text { D } & 46.6 & 58.9 & 65.4\end{array}$

In Figuur I verskyn 'n grafiese voorstelling van hierdie resultate.

Die volgende is opmerklik:

1. Die seuns het oor die algemeen beter as die meisies gepresteer.

2. Die twee plattelandse skole, C en D, het veral in standerds VII en VIII beter as die stedelike skole, $A$ en $B$, gepresteer.

3. Die meisies van skool A toon 'n baie reëlmatige styging in persentasie behaal in al drie die standerds.
4. Die seuns in standerd VII van skool $B$ het swakker as die van standerd VI gepresteer.

5. Met die uitsondering van skool $\mathrm{D}$ toon die lyn-grafieke 'n afwaartse neiging in standerd VII. (Ouderdom omtrent 14 jaar).

Toets 2. Die gemiddelde persentasies wat in Toets 2 behaal is, verskyn in Tabel III.

TABEL III.

Die gemiddelde persentasies in Toets 2 behaal.

SEUNS :

$\begin{array}{lccc}\text { Skool } & \text { St. VI } & \text { St. VII } & \text { St. VIII } \\ \text { A } & 37.8 & 35.1 & 49.5 \\ \text { B } & 38.7 & 34.7 & 43.9 \\ \text { C } & 33.8 & 41.2 & 57.7 \\ \text { D } & 37.6 & 47.3 & 55.4\end{array}$

\section{MEISIES :}

$\begin{array}{lccc}\text { Skool } & \text { St. VI } & \text { St. VII } & \text { St. VIII } \\ \text { A } & 28.4 & 32.6 & 41.1 \\ \text { B } & 30.7 & 28.1 & 31.7 \\ \text { C } & 31.9 & 31.8 & 47.5 \\ \text { D } & 36.6 & 40.4 & 53.3\end{array}$

Figuur 2 is ' $n$ grafiese voorstelling van hierdie resultate.

Die volgende is opmerklik:

1. In elke skool presteer die meisies swakker as die seuns van dieselfde skool.

2. Die seuns van die twee plattelandse skole $C$ en $D$, het in standerds VII en VIII beter gepresteer as die seuns van die stedelike skole A en B.

3. Die meisies van skool A toon ' $n$ reëlmatiger styging in prestasie as die van die ander skole. 
4. Die seuns van skole $A$ en $B$ en die meisies van skole $B$ en $C$ presteer swakker in standerd sewe as in standerd ses.

5. Met die uitsondering van die seuns van skool D, toon die lyngrafieke 'n afwaartse neiging in St. VII.

Daar is 'n duidelike ooreenkoms tussen Figuur 1 en Figuur 2.

Die korrelasiekwosiënt van die resultate van nie-rekenkundige en rekenkundige toetse gesamentlik is bereken. Dit verskyn in Tabel IV.

Die betroubaarheidsgrense $(95 \%$ basis) is bereken, dit is .09 bo en onder die gegewe waardes.

\section{TABEL IV.}

Die korrelasies tussen Toets 1 en Toets 2

$\begin{array}{ccc} & \text { en } 3 \text { gesamentlik. } & \\ \text { Standerd } & \text { Seuns } & \text { Meisies } \\ \text { VI } & 0.42 & 0.34 \\ \text { VII } & 0.49 & 0.56 \\ \text { VIII } & 0.52 & 0.52\end{array}$

Die hetroubaarheidsgrense is bereken met die hulp van die formule

$r \pm 2 \cdot \frac{1-r^{2}}{\sqrt{N}}$

Waar $r$ die korrelasiekwosiënt is, en $\mathrm{N}$ die aantal proefpersone.

Aangesien die normaliteit van die verdelings nie getoets is nie, is steeds van betroubaarheidsgrense gebruik gemaak.

Die duidendheid van die verskille in die gemiddelde aantal punte behaal, is getoets deur van die volgende formule gebruik te maak om die grense te bereken.

$$
\text { Grense }=X-X I \pm Z_{2} / \frac{S^{2}}{n}+\frac{S^{\prime 2}}{n^{4}}
$$

$\overline{\mathrm{X}}=$ die gemiddelde prestasie van die eerste groep.

$Z_{2}=2$ vir $95.46 \%$ basis.

$Z_{2}=3$ vir $99.73 \%$ basis.

$\mathrm{S}=$ die standaardafwyking van die eerste groep.

waar $S^{2}=$ variansie $=\frac{1}{n} \bar{Z}_{i}^{f} x_{i}^{2}-\left({ }_{n}^{1} \bar{Z}_{i}^{f} x\right)$

$X^{\prime}$, s' en n' is die ooreenkomstige simbole vir die tweede groep.

As nul tussen die grense lê, is die verskil nie duidend op die basis wat gebruik is nie.

Om die bespreking te vergemaklik sal ons vooraf afspreek dat onder "Wiskunde" net Algebra en Meetkunde verstaan word, terwyl Rekenkunde as ' $n$ aparte vak beskou word. Dit sluit aan by die gangbare gebruik in Suid-Afrika. Spreek ons egter van die "wiskundige verhoudingsbegrip" dan word Rekenkunde daarby ingesluit.

TABEL V.

Aantal lesperiodes vir rekenkunde en wiskunde

Lengte van St.VI St. VII St. VIII Skool Period. R. W. R. W. R. W. A $\quad 35$ min. $\quad 5 \quad 2 \quad 4 \quad 5545$ B $\quad 35$ min. 5 geen $2 \quad 5 \quad 2 \quad 5$

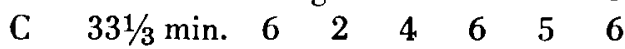

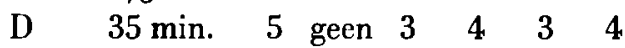

\section{TABEL VI.}

Die persentasie proefpersone wat sowel rekenkunde as wiskunde neem. SEUNS :

$\begin{array}{lccc}\text { Skool } & \text { St. VI } & \text { St. VII } & \text { St. VIII } \\ \text { A } & 100 & 97.5 & 78.4 \\ \text { B } & 0 & 100 & 84.4 \\ \text { C } & 53.1 & 100 & 98 \\ \text { D } & 0 & 87.4 & 92.6\end{array}$




\section{MEISIES :}

$\begin{array}{lccc}\text { Skool } & \text { St. VI } & \text { St. VII } & \text { St. VIII } \\ \text { A } & 22.2 & 3.1 & 20.8 \\ \text { B } & 0 & 9.8 & 11.1 \\ \text { C } & 57.6 & 10.4 & 20.8 \\ \text { D } & 0 & 40.8 & 54.2\end{array}$

Wanncer die grafiese voorstellings geraadpleeg word, is die invloed van die Rekenkunde- sowel as Wiskunde-onderwys duidelik. Dit is dus nie nodig om dit in besonderhede te bespreek nie. Ons stip nog net die volgende aan:

\section{Standerd VI:}

$53 \%$ van die seuns en $71 \%$ van die meisies kon nie minstens $40 \%$ van die sommetjies in die voorgeskrewe tyd reg doen nie. Die meerderheid standerd VI. leerlinge van hierdie vier skole beskik nie oor 'n voldoende verhoudingsbegrip om eweredigheidsomme met insig volgens die breukmetode te doen nie.

Die ontwilkeling in standerds VI, VII en VIII

Die persentasie wat deur die proefpersone vir die verhoudingsomme in standerds VI en VII behaal is, verskil nie duidend van mekaar nie. Ofskoon die standerd-agts al veel meer van die laerskool-eweredigheidsomme vergeet het, presteer hulle statisties duidend beter as die standerdsewes.

Moontlik vind 'n deurbraak van die verhoudingsbegrip cers op hierdie stadium plaas.

Toets 2: Vrae 4 en 5. Aan die wyse waarop hierdie twee vrae beantwoord is, is besondere aandag gegee. Vraag 4 vereis alleen aftrekking terwyl in vraag 5 eers 'n verhouding bepaal moet word. Dat skool C so goed gepresteer het, moet toegeskrywe word aan die feit dat daar besondere aandag aan die begrippe gegee word. By die ander skole was daar toenemende verwarring tussen die begrippe "soveel groter as" (vraag 4) en "soveel keer groter as" (vraag 5). Skool C het daardeur 'n voorsprong in al die toetse behaal. 'n Faktor wat dus 'n sterk invloed uitoefen, is behoorlike en intensiewe aandag aan begrippe soos "groter as", "so groot as", "soveel groter as", ,soveel keer so groot as", „soveel keer groter of kleiner as", „watter breuk is a van b?", „kleiner as", en ,soveel keer so klein as".

Die invloed van die aantal lesperiodes per week.

Rekenkunde: In die vier skole word die volgende aantal periodes in standerds VI, VII en VIII aan rekenkunde bestee.

Skool A: 5, 4, 4 .

Skool B: 5, 2, 2.

Skool C: 6, 4, 5 .

Skool D: 5, 3, 3 .

Laat ons die prestasies van die twee stedelike skole, $A$ en $B$, en die twee plattelandse skole, $C$ en $D$, met mekaar vergelyk. Ons bemerk onmiddellik dat ofskoon skool B skool A in standerd ses oortref, skool A, wat meer aandag aan Rekenkunde gee skool B in standerds sewe en agt ver oortref in beide die rekenkundige en nierekenkundige toetse. Die ooreenkoms in prestasies in die twee toetse is van besondere belang.

'n Soortgelyke verskynsel merk ons op wanneer ons skole $C$ en $D$ vergelyk. Die seuns van skool $\mathrm{C}$ presteer in beide toetse in standerds ses en sewe swakker as die 
in skool D, maar in St. VIII beter. Moontlik is die feit dat skool $C \mathbf{5}$ periodes per week aan Rekenkun J- bestee, teenoor die drie per week van skool $D$ afdoende verklaring. Die meisies van skool D vaar egter deurgaans beter as die van skool C in die rekenkundige toets. Dit kan egter verklaar word dat deur die verskil in aandag aan die Wiskunde-onderwys.

Wiskunde: Raadpleeg ons Tabel VI dan bemerk ons dat die volgende persentasies meisies Wiskunde in standerds VI, VII en VIII onderskeidelik neem:

$\begin{array}{llll}\text { Skool C: } & 57.6 & 10.4 & 20.8\end{array}$ $\begin{array}{llll}\text { Skool D: } & 0 & \mathbf{4 0 . 8} & \mathbf{5 4 . 2}\end{array}$

Die Wiskunde-onderwys in St. VI oefen nie veel invloed op die ontwikkeling van die wiskundige verhoudingsbegrip nit nie, maar in standerds VII en VIII word die invloed duidelik.

Die ontwikkeling van die verhoudingsbegrip wissel aansienlik van skool tot skool. In die eerste plek is dit toe te skrywe aan die wisselende aantal lesperiodes wat in die verskillende skole per week aan Rekenkunde-onderwys toegestaan word. 'Ten tweede hang dit af van die aandag wat begrippe in die onderwys van Rekenkunde geniet. In die derde plek oefen die Wiskunde-onderwys hier ook sy invloed uit - in standerd VI minder as in standerds VII en VIII.

Die ontwikkeling van die verhoudingsbegrip op rekenkundige gebied het vormende waarde vir die verhoudingsbegrip op nie-rekenkundige gebied.

Die verhoudingsbegrip en die onderwys.

Die middelbare skool: In Nederland gaan die leerlinge op min of meer dieselfde ouderdom as in Suid-Afrika na die middelbare skool. Kohnstamm het 'n soortgelyke Rekenkundetoets op kinders van 12 of 13 jaar toegepas; die resultaat was, in hoë mate bedroewend en verontrustend."19) P. M. van Hiele handel oor die aanvangsonderwys in Meetkunde. „In aanmerking daarvoor komen vooral het oppervlakte begrip, de breuken en de verhoudingen. Ervaringen van de laatste jaren hebben ons geleerd, dat van de drie genoemde onderwerpen de leerlingen vrijwel uitsluitend schijnkennis meebrengen".20)

Dat 'n gebrekkige verhoudingsbegrip een van die hoofoorsake is van rekenmoeilikhede op die middelbare skool, sien ons ook in verband met die breukbegrip. Cath sê: ,op de lagere school verdeelt men een appel of een taart en komt zo tot het begrip van een breuk. In het middelbaar onderwijs is een breuk een horizontale streep met een getal er boven en er onder".21) Tussen die laer en die middelbare skool moet die leerling dus op een of ander manier tot 'n behoorlike begrip van verhouding kom.

Die aansluiting tussen laer en middelbare onderwys.

Rekenkunde: In Suid-Afrika vorm die verhoudingsbegrip die einde van die Rekenkunde-onderwys aan die laerskool; dit behoort ook die begin van die Rekenkundeonderwys aan die middelbare skool te wees. Die strewe moet wees om die verhoudings. begrip, deur die veelvuldige oefening in die oplossing van eenvoudige probleme, te laat posvat. Ingewikkelde somme wat moet opgelos word volgens reëls wat van buite geleer moet word, is skadelik. 


\section{Die taak van die middelbare skool.}

In die eerste plek moet die verhoudingsbegrip sy ereplek ontvang as die saambindende faktor van die hele middelbare Rekenkunde-onderwys.

Twecdens moet die ietwat beperkte begripsvermoë van die leerlinge wat vir die cerste keer op die middelbare skool kom, in aanmerking geneem word. Dit verdien sterk oorweging dat die laer skool verhoudingsomme hoofsaaklik volgens die eenheidsmetode behoort te doen. Deur die broukmetode aan die middelbare skole oor te laat, ontvang die middelbare skool 'n spesifieke taak, wat die begripsvorming van die leerlinge betref. Daardeur sal dit ook moontlik wees om vrugbare koördinasie met Algebra en Meetkunde te bewerkstellig. Die begrip en begripsvorming moet op die voorgrond geplaas word.

\section{Algebra en Meetkunde.}

Die toetse het angetoon dat die leerlinge wat wel in st. VI Wiskundeonderrig ontvang na die eerste halfjaar nie beduidend beter gevaar het as die wat geen Wiskunde-onderrig in standerd VI ontvang het nie.

In die anvangswiskunde word te min aandag aan die verhoudingsbegrip gegee, met die gevolg dat daar weinig aansluiting by die laerskoolrekenkunde is. Hierdie saak is in Nederland ook ondersoek en „Mededelingen No. 23” van die „Nutsse-

\section{VOETNOTE:}

1. Boyer, C. B.: The concepts of the calcules, 15.

2. Ibid, 18 minarium voor paedagogiek aan de Universiteit van Amsterdam" kom in bladsy 14 tot die volgende slotsom: „Dit was in waarheid een pijnlijke verrassing".

Om deur die gebruikmaking van ver. houdings die Meetkunde-onderrig by die Rekenkunde te laat aansluit, is nuttiger as om met definisies, aksiomas en stellings te begin. Daarvoor geld Langeveld se waarskuwing „En mag ik daaruit... meedelen, dat wat logisch elementair is, dat psychologisch nog geenszins behoeft te zijn."22)

Waar die Rekenkunde en Meetkunde die verhoudingsbegrip by die leerling kan tuisbring, kan die Algebra hierop voortbou deur die bewerkings in formules vas te lê, nadat vooraf voldoende aandag an die hoofbewerkings met natuurlike getalle gegee is.

\section{Slotsom:}

1. In die Wiskunde het die verhoudingsbegrip deur al die eeue 'n sentrale plek beklee.

2. Leerlinge wat vir die eerste keer na die middelhare skool gaan het meesal nog geen behoorlike verhoudingsbegrip nie.

3. Die ontwikkeling van die wiskundige verhoudingsbegrip van leerlinge is bevorderlik vir hulle denke, ook op niewiskundige gebied.

Pretoria.

A. J. van Rooy. 
7. Langeveld, M. J.: Inleiding tot de studie der paedagogische psychologie van de middelbare schoolleeftijd, vijfde druk, 296.

8. Ibid, 297.

9. Ibid, 309.

10. Duncken, K.: Psychologie des produktiven Denkens, aangehaal deur Langeveld: Paed. psychologie, 242.

11. Langeveld: a.w., 400

12. Vinacke, W.: The psychology of thinking, 177.

13. Piaget, J.: The child's conception of num. ber, 10.

14. Wepener, F. C.: Die breukmetode versus die eenheidsmetode in die oplossing van eweredigheidsomme, Ongepubliseerde $M$. Educ.verhandeling, Stellenbosch, 81.

15. Nutsseminarium, Universiteit van Amsterdam; Mededelingen nr. 32, 19.

16. Langeveld; a.w., 152 en 153.

17. Ibid, 154.

18. Kohnstamm, Ph.: Keur uit het didactisch werk, 75 .

19. Mededelingen nr. 32, 18.

20. Van Hiele, P. M.: Pakkende materiaal ter inleiding van meetkundige grondbegrippen, Euclides, 30e Jaargang, 1954/55, v-vi, 251.

21. Cath: Jules Henri Poincare, Euclides, 30e Jaargang, 272.

22. Langeveld: a.w. 153. 